\title{
СТРАТЕГІЯ ЛІКУВАННЯ КАШЛЮКУ
}

\section{Н.О. Іванченко}

Львівський національний медичний університет ім. Данила Галицького, м. Львів, Україна

Ключові слова: кашлюк, лікування, антибіотики, інгаляційні

кортикостероїди.

Буковинський медичний вісник. T.25, № 2 (98).

C. 133-138.

DOI: $10.24061 / 2413-$ 0737.XXV.2.98.2021.22

E-mail: timknat@ukr.net
Резюме. Кашлюк, не зважаючи на те, щзо хвороба давно відома, досі залишається проблемою для усіх краӥн світу. Напад кашлю викликає не лиме фізичний дискомфорт пацієнта, а і значне негативне психоемочійне навантаження. Існуюча медикаментозна терапія до сьогодні не вирішує усіх проблем у лікуванні кашлюку.

Мета роботи - провести огляд літератури лікування кашлюку та оцінити ефективність використання інгаляиійних кортикостероїдів у дорослих пацієнтів із середньотяжким та тяжким перебігом хвороби.

Матеріал і методи. Опрацьовано протоколи та клінічні настанови лікування кашлюку, проведено аналіз 26 медичних карт стаціонарних хворих з діагнозом: «Кашлюк».

Висновок. Антибіотикотерапія є обов'язковим компонентом лікування кашлюку. Встановлена ефективність використання інгаляційних кортикостероїдів у дорослих пацієнтів із середньотяжким та тяжким перебігом кашлюку.

\section{СТРАТЕГИЯ ЛЕЧЕНИЯ КОКЛЮША}

\section{Н.А. Иванченко}

Ключевые слова: коклюш, лечение, антибиотики, ингаляцуионные кортикостероидь.

Буковинский медицинский вестник. T.25, № 2 (98). С. 133-138.
Резюме. Коклюш несмотря на то, что болезнь давно известна, до сих пор остается проблемой для всех стран мира. Приступ кашля вызывает не только физический дискомфорт пациента, но и значительное негативное психоэмоциональное напряюение. Сущчествующая медикаментозная терапия до сих пор не решает всех проблем в лечении коклюша.

Цель работы - провести обзор литературы способов лечения коклюша и оиенить эффективность использования ингаляциионных кортикостероидов у взрослых пациентов со среднетяжелым и тяжелым течением болезни. Материал и методы. Изучено протоколь и клинические рекомендаичи лечения коклюша, проведен анализ 26 медиичнских карт стацчонарных паичентов с диагнозом: «Коклюш».

Выводы. Антибиотикотерапия является обязательным компонентом лечения. Установлена эффективность использования ингаляциионных кортикостероидов у взрослых пацчентов со среднетяжельм и тяжельм течением коклюша.

\section{PERTUSSIS TREATMENT STRATEGIES}

\section{N.O. Ivanchenko}

Key words: pertussis, treatment, antibiotics, inhaled corticosteroids.

Bukovinian Medical Herald. V.25, № 2 (98). P. 133-138.
Abstract. Whooping cough, despite the fact that the disease has long been known, still remains a problem for all countries. Cough attacks can cause not only physical discomfort to the patient, but also a significant negative psycho-emotional load. Existing drug therapy to date does not solve all the problems in the treatment of whooping cough.

The aim of our study was to conduct a literature review of pertussis treatment and evaluate the efficacy of inhaled corticosteroids in adult patients with mod- 
erate to severe disease.

Material and methods. Guidelines for the treatment of whooping cough were studied, and 26 medical records of inpatients with the diagnosis of "Pertussis" were analysed.

Conclusion. Antibiotic therapy is a mandatory component of treatment. The effectiveness of inhaled corticosteroids in adult patients with moderate to severe whooping cough has been established.

Вступ. Зазвичай вважається, що кашлюк є хворобою дитячого віку. Проте у дорослих теж не є рідкістю, але не завжди діагностується [1]. Клінічна картина в дорослих може бути від незначного покашлювання до класичної розгорнутої з нападами кашлю, «репризами», блюванням по завершенню нападів. Саме «нетиповий» перебіг кашлюку в дорослих часто спричиняє труднощі при діагностиці [2]. Можуть спостерігатися біль у грудній клітці, біль голови, кровохаркання, аритмія, синкопальні стани. Відповідно до клінічного перебігу виділяють ступені тяжкості кашлюку: легкий - частота нападів кашлю до 15 на добу, кількість реприз - до 5, середньотяжкий - частота нападів кашлю до 25 на добу, кількість реприз до 10, тяжкий - частота нападів кашлю більше 25 на добу, кількість реприз понад 10. Загальний стан пацієнта порушується при всіх формах перебігу хвороби. Bordetela pertussis уражає виключно епітелій дихальних шляхів, а провідне місце в патогенезі кашлюку належить численним токсинам, антигенам, які виділяє збудник [3]. Токсини тривало циркулюють у кров'яному руслі, спричиняючи як симптоми захворювання, так і виражену імуносупресію - кашлюкову анергію.

Мета роботи - провести огляд літератури лікування кашлюку та оцінити ефективність використання інгаляційних кортикостероїдів у дорослих пацієнтів із середньотяжким та тяжким перебігом хвороби.

Матеріал і методи. Опрацьовано протоколи та клінічні настанови кашлюку, проведено аналіз 26 медичних карт стаціонарних хворих пацієнтів старше 18 років 3 діагнозом: «Кашлюк», які проходили лікування у Львівській обласній інфекційній клінічній лікарні (ЛОІКЛ).

У різні часи спостерігались різноманітні підходи до лікування кашлюку. Наприклад, на початку XVIII сторіччя використовували перегорик, створений професором Лейденського університету Ла Мотом. У «Лондонській фармакопеї» 1886 року на основі перигорика був перепис камфорного настою опію, який використовувався в тому числі для лікування кашлюку. У стародавньому Китаї кашлюк лікували різноманітними трав'яними зборами. Китайські фітотерапевти, у тому числі доктор Цін Зай Чжан, наводять дослідження, що показують ефективність хуанського ліану (кореневища коптису radix stemonae) для лікування кашлюку. Катаральний період кашлю в Китаї лікують травами: Сі Сінь, Ма Хуанг, Спі Ви та Джу Хуа, Сюань Фу Хуа, Цянь Ху, Чжуан Бей Му та Бан Ся, бай бу, син рен, Ліан Ціао. Використовують найрізноманітніші композиції з цих трав [4]. На сьогоднішній день «золотим стандартом» лікування кашлюку є антибіотикотерапія, яка також призначається як профілактика. Проте існують відмінності у використанні груп антибіотиків, тривалості терапії. Якщо антибіотикотерапія розпочата через два тижні після появи симптомів, то вона призначається з метою епідеміологічної безпеки і не впливає на клінічний перебіг [5]. Еритроміцин упродовж 14 днів є стандартним лікуванням, рекомендованим Американською академією педіатрії, тоді як у Канаді рекомендується 10-денний курс лікування [6]. Е.І. Гальперин та його колеги довели, що 7-денне лікування еритроміцином настільки ж ефективне, як і 14-денне лікування. Еритроміцин, зазвичай, призначають у чотири прийоми. На основі результатів in vitro хінолони також можуть бути альтернативою для дорослих. Піперацилін та цефалоспорини третього покоління можуть використовуватися як комбінована терапія для пацієнтів із пневмонією [7]. British Medical Journal основним аспектом лікування зазначає використання антибіотиків: азитроміцин, кларитроміцин, еритроміцин [8]. Триметоприм/сульфаметоксазол (TMP/SMX) рекомендовано призначати пацієнтам 3 алергією на макроліди або резистентністю до них за відсутності протипоказів. Для вагітних препаратом вибору є еритроміцин. Рекомендована тривалість лікування становить сім діб. Постконтактна профілактика рекомендована вагітним жінкам із терміном гестації > 32 тижні, які не були щеплені протягом останніх п'яти років. У разі призначення через три тижні після початку кашлю, лікування антибіотиками може мати обмежену ефективність [9]. Американський центр з контролю за інфекційними хворобами (CDC) основу лікування кашлюку також вбачає у призначенні антибіотиків 3 групи макролідів: азитроміцин, кларитроміцин, еритроміцин. Раннє призначення антибіотиків у катаральному періоді може сприяти зменшенню інтенсивності періоду спазматичного кашлю. FDA у 2013 році опублікувало застереження щодо використання азитроміцину пацієнтами з аритмією, оскільки азитроміцин може викликати подовження інтервалу QT [10]. Головною метою лікування антибіотиками є зниження контагіозності та розповсюдження хвороби. Для ефективності терапії іiї необхідно розпочати протягом 1-2 тижнів після виникнення симптомів. Тобто, рекомендовано негайно розпочинати лікування після відбору матеріалу на виявлення Bordetella pertussis методом ПЛР або встановлення клінічного діагнозу на основі симптомів та епідеміологічної ситуації. Якщо в пацієнта симптоми тривають довше одного місяця, лікування антибіотиками недоцільне. Повторні курси антибіотикотерапії неефек- 
Scientific reviews

тивні. Тривалість ізоляції пацієнта повинна становити п’ять днів від початку антибактеріальної терапії. Якщо симптоми тривають довше ніж три тижні, ізоляція недоцільна. Настанови на засадах доказової медицини створені DUODECIM Medical Publications, Ltd. «Настанова 00618. Кашлюк» рекомендують для антибіотикотерапії препарат вибору азитроміцин упродовж п'яти днів у дозі 500 мг у перший день і по 250 мг/добу наступні чотири дні. Рокситроміцин і кларитроміцин $є$ альтернативними препаратами для лікування. Амоксицилін або цефалоспорини неефективні [11]. В огляді бібліотеки Cochrane припускається, що недостатньо доказів щодо ефективності профілактичної антибіотикотерапії кашлюку серед контактних. У двох описаних дослідженнях оцінки ефективності хіміопрофілактики еритроміцином встановлено, що клінічні симптоми були незначно менш вираженими (не статистично значущими) у групі, що приймала еритроміцин, ніж у групі плацебо. Кількість контактних осіб, у яких бактеріологічним методом виділена Bordetella pertussis після профілактичного лікування еритроміцином, становила лише $2,1 \%$ порівняно 3 контрольною групою (7,4\%). Таким чином, профілактичне лікування макролідами незначно сприяє зменшенню вираженості клінічних проявів кашлюку, проте суттєво зменшує частоту виявлення культури Bordetella pertussis, запобігаючи вторинній передачі інфекції. Еритроміцин варто використовувати для лікування жінок на ранніх термінах вагітності. Жінкам 3 діагнозом кашлюк в останній триместр вагітності рекомендується еритроміцин для запобігання передачі кашлюку немовляті. Ризики щодо зв'язку між лікуванням еритроміцином у матері (на пізніх термінах вагітності) та гіпертрофічним пілоростенозом у немовлят відсутні [12].

3 моменту запровадження програми вакцинації проти кашлюку для вагітних в Англії охоплення було понад 5060\% у грудні 2014 року. Тому багато вагітних жінок, які контактували з хворими на кашлюк після 32 тижня були вакциновані і не потребували хіміопрофілактики. Для осіб, у яких макроліди протипоказані, рекомендовано призначати TMP/SMX. Згідно з Протоколом лікування кашлюку у Великобританії призначається кларитроміцин - 500 мг 2 рази на добу сім днів або азитроміцин 1 табл. 1 раз на добу три дні. Вагітним рекомендовано еритроміцин - 500 мг 4 рази на добу сім днів. При антибіотикорезистентності рекомендовано TMP/SMX 960 мг 2 рази на добу сім днів [13]. У Китаї спостерігалося збільшення резистентних до еритроміцину ізолятів Bordetella pertussis з 2013 року. Зокрема, 167 ізолятів у Китаї були протестовані на чутливість до антибіотиків. Згідно з одержаними результатами усі, крім чотирьох ізолятів, були стійкими до еритроміцину. Секвенування геномів і філогенетичний аналіз виявили три незалежні еритроміцинорезистентні лінії. У всіх ізолятів виявлено мутацію в гені $23 \mathrm{~S}$ рРНК. Дослідження, проведене в Китаї виявило, що для всіх ізолятів Bordetella pertussis TMP/SMX був чутливим і його варто рекомендувати пацієнтам, інфікованим резистентною до еритроміцину Bordetella pertussis. Припущено, що ізоляти, які цир- кулюють у Китаї, відрізняються від таких у західних країнах [14]. У США такі антибіотики, як ампіцилін, амоксицилін, тетрациклін, хлорамфенікол, фторхінолони (наприклад, ципрофлоксацин, левофлоксацин, офлоксацин, моксифлоксацин), і цефалоспорини виявляють різні рівні пригнічення росту Bordetella pertussis in vitro. Клінічна ефективність цих засобів для лікування кашлюку не доведена. Ампіцилін і амоксицилін були неефективними при лікуванні кашлюку, оскільки культура збудника виділялась 3 носоглотки після курсу лікування. Мінімальна інгібуюча концентрація цефалоспоринів для Bordetella pertussis є неприпустимо високою [15]. Протокол лікування кашлюку республіки Казахстан передбачає як етіотропну терапію мідекаміцин 3 рази на добу впродовж семи днів або азитроміцин у першу добу 1 г, у подальшому 500 мг 1 раз на добу чи амоксицилін 3 клавулановою кислотою 3 рази на добу 7-10 днів. Можливе лікування цефуроксимом 3 рази на добу 7-10 днів [16]. У Росії рекомендована антибіотикотерапія та антибіотикопрофілактика як макролідами, так і цефалоспоринами 3-го покоління. У Казахстані патогенетичну терапію рекомендовано амінофілін довенно 3 рази на добу впродовж семи днів. Для зменшення інтенсивності кашлю вводять діазепам дом'язово 2 рази на добу. Рекомендують бутамірат по 20 крапель 3 рази на добу 7-10 днів. Глюкокортикостероїди рекомендовані при тяжкому перебігу кашлюку з апное, зниженні сатурації. Препаратами вибору є гідрокортизон або дексаметазон. При судомах призначають фенобарбітал, діазепам, натрію оксибутират [15]. У Росії на початку хвороби рекомендований $\gamma$-глобулін. Використовуються протикашльові засоби центральної дії: синекод та інші. Доцільно призначати антигістамінні середники, транквілізатори, аміназин [17]. British Medical Practic зазначають, що як місцеву протизапальну та симптоматичну терапію варто розглядати кортикостероїди та салбутамол, які можуть зменшити частоту нападів кашлю, але перед їх використанням потрібно провести додаткове оцінювання ризиків. Ефективність специфічного кашлюкового імуноглобуліну вивчається [8]. У довіднику з фітотерапії для лікування кашлюку рекомендований відвар чебрецю, кореня солодки, насіння кропу [4]. За результатами ще одного огляду бібліотеки Cochran в січні 2014 року проведено 12 досліджень з 572 учасниками. На підставі цих досліджень доведено, що антигістамінні препарати, протикашлюковий імуноглобулін та салбутамол не зменшували числа нападів кашлю. Використання імуноглобуліну не скоротило кількості днів лікування в стаціонарі [12]. У Росії рекомендовано використовувати специфічний протикашлюковий $\gamma$-глобулін для лікування кашлюку на ранній стадії по 3 мл три дні поспіль, далі через день три введення. В Україні даний препарат не виробляється. Проте в інструкції до простого людського імуноглобуліну серед показів $є$ профілактика кашлюку. Протоколом Росії рекомендоване перебування на свіжому повітрі при температурі не нижче $10^{\circ} \mathrm{C}$, киснева терапія. Нейролептичні засоби (аміназин, пропазин) завдяки безпосередньому впливу 
Наукові огляди

на центральну нервову систему можуть полегшити стан хворих, сприяють зменшенню частоти та тривалості спазматичного кашлю. Вводять дом'язово $2,5 \%$ розчин аміназину 1-3 мг/кг препарату на добу на 3-5 мл 0,250,5\% розчині новокаїну. Добову дозу слід поділити на 3 рази на курс 7-10 діб. Наркотичні засоби протипоказані, оскільки пригнічують дихальний центр. При тяжких випадках призначають глюкокортикостероїди впродовж 8-10 діб. При загрожуючих життю станах може бути застосована екстракорпоральна мембранна оксигенація (ЕСMO), яка забезпечує серцеву та респіраторну підтримку. Найвищу летальність відзначають у хворих на кашлюк з гіперлейкоцитозом. Проводилось дослідження, коли вводили моноклональні антитіла миші, специфічні для пертактину експериментальним тваринам, зараженим Bordetella pertussis. BT Nguyen у 2015 році виявив, що це лікування було більш ефективним, ніж замінне переливання крові при гіперлейкоцитозі [18]. Описані випадки успішного лікування термінальних хворих після проведення замінного переливання крові. Коли кашлюк супроводжується гіперлейкоцитозом, летальність наближається до 80\%. Незрілі лейкоцити були виявлені у легеневих артеріолах, малих артеріях і венулах. Методи, спрямовані на зменшення кількості лейкоцитів, можуть покращити прогноз пацієнтів. $€$ повідомлення про трьох пацієнтів, яким було проведено замінне переливання крові в умовах тяжкого кашлюку та гіперлейкоцитозу. Серед запропонованих методів симптоматичного лікування кашлюку є $\alpha$-2-адренергічні агоністи, антигістамінні препарати та антагоністи рецепторів лейкотриєну (LTRA) [17].

Симптоматична терапія бронхолітиками, кортикостероїдами, протикашльовими та антигістамінними засобами не завжди ефективна. Запропоновано лікування з використанням елементів мануальної терапії. Важливе значення має подразнення рефлексогенних зон діафрагми, 6-12 пар ребер, поперекових хребців L1-3, остистих відростків шийного відділу хребта (С3-С5). Також важливою є рефлекторна стимуляція ділянки атланта. Більшість джерел рефлексогенного лікування кашлюку були опубліковані протягом першої чверті 20-го століття. Загальновизнані методи включали методи іммобілізації, методи лімфодренажу в шийній та грудній ділянках [19].

Нами проаналізована ефективність використання інгаляційних кортикостероїдів при лікуванні хворих на середньотяжкі та тяжкі форми кашлюку. Під спостереженням перебували 26 пацієнтів, які проходили стаціонарне лікування у ЛОІКЛ. Шістнадцять пацієнтів одержували інгаляційні кортикостероїди в складі комплексної терапії (діюча речовина будесонід 0,4) двічі на добу через небулайзер. Десять пацієнтів проходили курс

\section{Результати анкетування паціснтів 3 кашлюком}

Таблиця

\begin{tabular}{|c|c|c|c|c|c|}
\hline № п/п & Симптом & $\begin{array}{c}\text { Пацієнти } \\
\text { до IКС, } \\
\mathrm{n}=16\end{array}$ & $\begin{array}{c}\text { Пацієнти з IКС } \\
\text { 5-й день, } \\
\text { n= } 16\end{array}$ & $\begin{array}{c}\text { Пацієнти без } \\
\text { ІКС } \\
1 \text {-й день, n= } 10\end{array}$ & $\begin{array}{c}\text { Пацієнти без } \\
\text { ІКС } \\
\text { 5-й день, n= } 10\end{array}$ \\
\hline 1 & Інтенсивність нападів кашлю & $8 \pm 1,2$ & $6 \pm 1,2$ & $8 \pm 0,8$ & $8 \pm 0,8$ \\
\hline 2 & Тривалість нападів кашлю & $9 \pm 0,2$ & $5 \pm 0,8 \# \#$ & $9 \pm 0,3$ & $8 \pm 0,6 * *$ \\
\hline 3 & Частота нападів кашлю & $9 \pm 0,7$ & $7 \pm 0,9$ & $9 \pm 0,4$ & $9 \pm 0,4$ \\
\hline 4 & Блювання & $2 \pm 0,2$ & $2 \pm 0,1$ & $3 \pm 0,3$ & $2 \pm 0,5$ \\
\hline 5 & Головний біль & $5 \pm 1,2$ & $7 \pm 1,1$ & $6 \pm 0,8$ & $6 \pm 0,8$ \\
\hline 6 & Біль у грудній клітці & $3 \pm 0,5$ & $3 \pm 0,5$ & $4 \pm 0,2$ & $4 \pm 0,2$ \\
\hline 7 & Апное & $2 \pm 0,3$ & $2 \pm 0,2$ & $1 \pm 0,2$ & $1 \pm 0,2$ \\
\hline 8 & Задишка & $8 \pm 0,9$ & $4 \pm 0,9 \# \#$ & $7 \pm 0,8$ & $7 \pm 0,8^{*}$ \\
\hline 9 & Нетримання сечі & $2 \pm 0,4$ & $2 \pm 0,3$ & $1 \pm 0,25^{*}$ & $1 \pm 0,25^{*}$ \\
\hline 10 & Тривожність & $9 \pm 0,2$ & $4 \pm 1,1 \# \#$ & $8 \pm 0,25^{* *}$ & $7 \pm 0,5^{*}$ \\
\hline 11 & Порушення сну & $5 \pm 0,8$ & $5 \pm 0,9$ & $6 \pm 0,5$ & $6 \pm 0,5$ \\
\hline 12 & Порушення уваги & $6 \pm 0,9$ & $6 \pm 1,1$ & $6 \pm 0,25$ & $6 \pm 0,25$ \\
\hline 13 & «Закладеність» носа & $4 \pm 0,8$ & $3 \pm 0,9$ & $4 \pm 0,8$ & $4 \pm 0,8$ \\
\hline 14 & «Ком» у горлі & $6 \pm 0,9$ & $4 \pm 1,1$ & $6 \pm 0,5$ & $6 \pm 0,5$ \\
\hline 15 & Запаморочення & $6 \pm 1,2$ & $8 \pm 1,1$ & $6 \pm 1,4$ & $6 \pm 1,4$ \\
\hline
\end{tabular}

\section{Примітки:}

* - наявна достовірна $(\mathrm{p}<0,05)$ різниця між аналогічними періодами різних груп;

** - наявна достовірна ( $<0,01)$ різниця між аналогічними періодами різних груп;

\# - наявна достовірна ( $<0,05)$ різниця між даними до лікування та на 5-й день у межах групи;

\#\# - наявна достовірна ( $<<0,01)$ різниця між даними до лікування та на 5-й день у межах групи. 
лікування без застосування інгаляційних кортикостероїдів. Будесонід - це активний синтетичний глюкокортикоїд, характеризується місцевою протизапальною дією за рахунок високої ліпофільності і здатності проникати внутрішньоклітинно, зв'язуватися з глюкокортикоїдними рецепторами. Здатність будесоніду утворювати кон'югати із жирними кислотами пояснює механізм місцевої протизапальної активності уповільненого типу і високий рівень терапевтичної ефективності препарату.

Не виявлено відмінностей тривалості стаціонарного лікування між даними пацієнтами, середнє значення становило $14 \pm 2$ дні. Нами застосований метод крос-секційного дослідження. Запропоновано 16 пацієнтам заповнити анкету щодо вираженості симптомів захворювання до призначення інгаляційних кортикостероїдів та на 5-ту добу від початку лікування за 10 - бальною шкалою. Аналогічну анкету щодо вираженості симптомів заповнили пацієнти, у курсі лікуванні яких інгаляційні кортикостероїди не використовувались (табл).

За результатами проведеного дослідження встановлено, що використання інгаляційних кортикостероїдів зменшує тривалість та інтенсивність нападів кашлю (наявна достовірна $(\mathrm{p}<0,01)$ різниця між даними до лікування та на 5-й день у межах групи). Також зменшилось відчуття задишки у пацієнтів, що приймали інгаляційні кортикостероїди та тривожність (наявна достовірна $(\mathrm{p}<0,01)$ різниця між даними до лікування та на 5-й день у межах групи, та наявна достовірна $(\mathrm{p}<0,01)$ різниця між аналогічними періодами різних груп). У той же час збільшились скарги на запаморочення, головний біль. Порушення сну, уваги, нетримання сечі, апное, біль у грудній клітці та блювання не зазнали змін при лікуванні інгаляційними кортикостероїдами.

\section{Висновок}

Етіотропна терапія повинна призначатись пацієнтам одразу після встановлення клінічного діагнозу та відбору матеріалу для бактеріологічного дослідження або дослідження методом ПЛР. Зростає частота виявлення Bordetella pertussis, резистентних до азитроміцину. Слід розглядати можливість використання TMP/SMX у лікуванні кашлюку. Встановлена доцільність використання інгаляційних кортикостероїдів у дорослих пацієнтів із середньо-тяжким та тяжким перебігом кашлюку.

\section{Список літератури}

1. Centers for Disease Control and Prevention. Pertussis (whooping cough) [Інтернет] [Цитовано: 2017 сер 7]. Доступно: https://www. cdc.gov/pertussis/about/signs-symptoms.html.

2. Polinori I, Esposito S. Clinical Findings and Management of Pertussis. Adv Exp Med Biol. 2019;1183:151-60. DOI: 10.1007/5584_2019_410.

3. Zycinska K, Cieplak M, Chmielewska M, Nitsch-Osuch A, Klaczkow A, Hadzik-Blaszczyk M, et al. Whooping Cough in Adults: A Series of Severe Cases. Adv Exp Med Biol. 2017;955:47-50. DOI: 10.1007/5584_2016_167.

4. Гарна СВ. Сучасна фітотерапія. Харків: «Друкарня Мадрид»; 2016. 580 с.

5. Кашель. Адаптована настанова на клінічних доказах. ДЕЦ. MO3 [Інтернет]. [Цитовано 2015 p]. Доступно: https://dec.gov.ua/ wpcontent/uploads/2019/11/2015_327akn_kashel.pdf.

6. Bocka J, Steele R. Pertussis Workup. Medscape [Інтернет]
[Цитовано 2019 p]. Доступно: https://emedicine.medscape.com/ article/967268-overview.

7. Lauria AM, Zabbo CP. Pertussis. 2021 Jan 7. In: StatPearls [Internet]. Treasure Island (FL): StatPearls Publishing; 2021 Jan.

8. Pertussis. British Medical Journal [Інтернет] [Цитовано 2017 p]. Доступно: https://bestpractice.bmj.com/topics/en-us/682.

9. Di Mattia G, Nicolai A, Frassanito A, Petrarca L, Nenna R, Midulla F. Pertussis: New preventive strategies for an old disease. Paediatr Respir Rev. 2019 Feb;29:68-73.

10. Pertussis (whooping cough). Centers for Disease Control and Prevention [Інтернет] [Цитовано 2017 p]. Доступно: https://www. cdc.gov/pertussis/clinical/treatment.html.

11. Настанова 00618. Кашлюк. DUODECIM Medical Publications, Ltd. [Інтернет] [Цитовано 2018 p]. Доступно: https:// www.guidelines.moz.gov.ua.

12. Wang K, Bettiol S, Thompson MJ, Roberts NW, Perera R, Heneghan CJ, et al. Symptomatic treatment of the cough in whooping cough. Cochrane Database Syst Rev. 2014 Sep 22;2014(9):CD003257.

13. Guidelines for the Public Health Management of Pertussisin England. Produced by the Pertussis Guidelines Group [Internet] [2018]. Access: https://assets.publishing.service.gov.uk/government/ uploads/system/uploads/attachment_data/file/762766/Guidelines for_the_Public_Health_management_of_Pertussis_in_England.pdf.

14. Xu Z, Wang Z, Luan Y, Li Y, Liu X, Peng X, et al. Genomic epidemiology of erythromycin-resistant Bordetella pertussis in China. Emerg Microbes Infect. 2019;8(1):461-70.

15. Kline JM, Lewis WD, Smith EA, Tracy LR, Moerschel SK. Pertussis: a reemerging infection. Am Fam Physician. 2013 Oct $15 ; 88(8): 507-14$.

16. Клинический протокол диагностики и лечения коклюша и паракоклюша у детей. Протокол № 9 Министерства здравоохранения и социального развития Республики Казахстан. [Інтернет] [Цитовано 2016 p]. Доступно: www.rcrz.kz > docs > clinic_protocol > Педиатрия > 04_Коклюш.

17. Scanlon KM, Skerry C, Carbonetti NH. Novel therapies for the treatment of pertussis disease. Pathog Dis. 2015 Nov;73(8):ftv074.

18. Carbonetti NH. Pertussis leukocytosis: mechanisms, clinical relevance and treatment. Pathog Dis. 2016;74(7):ftw087.

19. Liem T. Osteopathic Manipulative Treatment for Pertussis in the 19th and 20th Centuries: A Structured Historical Literature Review. J Am Osteopath Assoc. 2019;119(2):116-25.

\section{References}

1. Centers for disease control and prevention. Pertussis (whooping cough) [Internet] [2017 aug 7]. Available from: https://www.cdc.gov/ pertussis/about/signs-symptoms.html.

2. Polinori I, Esposito S. Clinical findings and management of pertussis. Adv Exp Med Biol. 2019;1183:151-60. DOI: 10.1007/5584_2019_410.

3. Zycinska K, Cieplak M, Chmielewska M, Nitsch-Osuch A, Klaczkow A, Hadzik-Blaszczyk M, et al. Whooping Cough in Adults: A Series of Severe Cases. Adv Exp Med Biol. 2017;955:47-50. DOI: 10.1007/5584_2016_167.

4. Harna SV. Suchasna fitoterapiia [Modern phytotherapy]. Kharkiv: «Drukarnia Madryd»; 2016. 580 p. (in Ukrainian).

5. Kashel. Adaptovana nastanova na klinichnykh dokazakh [Cough. Adapted clinical guidelines]. DETs. MOZ [Internet]. 2015. Available from: https://dec.gov.ua/wpcontent/uploads/2019/11/2015_327akn kashel.pdf. (in Ukrainian).

6. Bocka J, Steele R. Pertussis Workup. Medscape [Internet] [2019]. Available from: https://emedicine.medscape.com/ article/967268-overview.

7. Lauria AM, Zabbo CP. Pertussis. 2021 Jan 7. In: StatPearls [Internet]. Treasure Island (FL): StatPearls Publishing; 2021 Jan.

8. Pertussis. British Medical Journal [Internet] [2021]. Available from: https://bestpractice.bmj.com/topics/en-us/ 682 .

9. Di Mattia G, Nicolai A, Frassanito A, Petrarca L, Nenna R, Midulla F. Pertussis: New preventive strategies for an old disease. Paediatr Respir Rev. 2019 Feb;29:68-73. DOI: 10.1016/j. prrv.2018.03.011. 


\section{Наукові огляди}

10. Pertussis (whooping cough). Centers for disease control and prevention [Internet] [2017]. Available from: https://www.cdc.gov/ pertussis/clinical/treatment.html.

11. Nastanova 00618. Kashlyuk [Attitude. Whooping cough]. DUODECIM Medical Publications, Ltd. [Internet] [2018]. Available from: https://www.guidelines.moz.gov.ua. (in Ukrainian).

12. Wang K, Bettiol S, Thompson MJ, Roberts NW, Perera R, Heneghan CJ, et al. Symptomatic treatment of the cough in whooping cough. Cochrane Database Syst Rev. 2014 Sep 22;2014(9):CD003257. DOI: 10.1002/14651858.CD003257.pub5.

13. Guidelines for the Public Health Management of Pertussisin England. Produced by the Pertussis Guidelines Group [Internet] [2018]. Available at: https://assets.publishing.service.gov.uk/government/ uploads/system/uploads/attachment_data/file/762766/Guidelines_ for_the_Public_Health_management_of_Pertussis_in_England.pdf.

14. Xu Z, Wang Z, Luan Y, Li Y, Liu X, Peng X, et al. Genomic epidemiology of erythromycin-resistant Bordetella pertussis in China. Emerg Microbes Infect. 2019;8(1):461-70. DOI: 10.1080/22221751.2019.1587315.
15. Kline JM, Lewis WD, Smith EA, Tracy LR, Moerschel SK. Pertussis: a reemerging infection. Am Fam Physician. 2013 Oct 15;88(8):507-14

16. Klinicheskiy protokol diagnostiki i lecheniya koklyusha i parakoklyusha u detey. Protokol № 9 Ministerstva zdravookhraneniya i sotsial'nogo razvitiya Respubliki Kazakhstan [Clinical protocol for the diagnosis and treatment of pertussis and parapertussis in children. Protocol No. 9 of the Ministry of Health and Social Development of the Republic of Kazakhstan] [Internet] [Citen 2016 p]. Available from: https://diseases.medelement.com/disease/коклюш/14852 (in Russian).

17. Scanlon KM, Skerry C, Carbonetti NH. Novel therapies for the treatment of pertussis disease. Pathog Dis. 2015 Nov;73(8):ftv074. DOI: $10.1093 /$ femspd/ftv074.

18. Carbonetti NH. Pertussis leukocytosis: mechanisms, clinical relevance and treatment. Pathog Dis. 2016;74(7):ftw087. DOI:10.1093/ femspd/ftw087.

19. Liem T. Osteopathic manipulative treatment for pertussis in the 19th and 20th centuries: a structured historical literature review. J Am Osteopath Assoc. 2019;119(2):116-25. DOI: 10.7556/jaoa.2019.018.

\section{Відомості про автора}

Іванченко Наталія Олександрівна - асистент кафедри інфекційних хвороб Львівського національного медичного університету імені Данила Галицького, м. Львів, Україна.

\section{Сведения об авторе}

Иванченко Наталия Александрова - ассистент кафедры инфекционных болезней Львовского национального медицинского университета имени Данила Галицького, г. Львов, Украина.

Information about the author

Nataliya Oleksandrivna Ivanchenko - Assistant Professor, Department of Infectious Diseases, Danylo Halytsky Lviv National Medical University, Lviv, Ukraine.

Надійила до редакціiі 4.03.2021

Рецензент - Москалюк В.Д.

(C) Н.О. Іванченко, 2021 